\title{
Clinico-epidemiological study of donovanosis in Durban, South Africa
}

\author{
N O'Farrell
}

\begin{abstract}
Objective To describe the epidemiological and clinical features of donovanosis and their relevance to the possible coincident risk of HIV-1 transmission in patients attending an STD clinic.
\end{abstract}

Design Assessment of patients with donovanosis diagnosed by the detection of Donovan bodies on tissue smears stained by the RapiDiff technique.

Setting City Health STD Clinic, King Edward VIII Hospital, Durban, South Africa.

Participants One hundred and seventy one patients with donovanosis.

Results Donovan bodies were detected in 171 (130 men, 41 women). Ulcers were present for longer than 28 days in 72 $(55 \cdot 4 \%)$ men and $19(46 \cdot 3 \%)$ women. Ninety five $(55 \cdot 6 \%)$ came from rural areas. Lesions were ulcero-granulomatous in 162, hypertrophic in eight and necrotic in one. Anal lesions were detected in one woman. Only one of 21 regular sexual partners examined was infected with donovanosis. Complete healing was observed in $41(24 \%)$ who attended for follow up. Extensive lesions were sometimes observed in pregnant women. Serological tests for syphilis were positive in $40(23 \cdot 4 \%)$. HIV-1 antibodies were detected in 4/48 men and 0/15 women who underwent HIV testing. Donovanosis ulcers in three HIV-1 seropositive men were cured by standard antibiotic therapy.

Conclusions Delay in presentation, extensive areas of genital ulceration and lack of co-existent infection with donovanosis among sexual partners were notable features. Primary health care facilities in rural areas do not appear to be providing an adequate service for patients with donovanosis. HIV control programmes should consider specific measures aimed at eradicating donovanosis in areas where the condition is prevalent.

(Genitourin Med 1993;69:108-111)

City Health STD Clinic, King Edward VIII Hospital, Durban, Natal, South Africa N O'Farrell

Address correspondence to: Dr N O'Farrell

Lydia Department

St Thomas' Hospital

London SE1, UK vanosis has received little mention in the medical literature and has not been regarded as a significant problem. ${ }^{12}$ Few, if any, STD clinics or outpatient departments undertake routine tests for donovanosis and the diagnosis is usually made either clinically or by histological examination of tissue sections.

A study of the microbial aetiology of GUD in Durban in 1985 detected no cases of donovanosis. ${ }^{3}$ However, following the introduction of a rapid diagnostic test for the detection of Donovan bodies, ${ }^{4}$ an increase in the numbers of cases in Durban suggested the condition may have been overlooked. STDs, particularly GUD, facilitate the transmission of $\mathrm{HIV}-1$ and the WHO has recommended that STD services be strengthened as part of National AIDS Control Programmes. ${ }^{5}$ In Durban HIV-1 infection is escalating rapidly and there is a highly significant risk of HIV infection in men with donovanosis. ${ }^{6}$ This study was therefore undertaken to investigate the clinical and epidemiological features of donovanosis relevant to the possible coincident risk of HIV-1 transmission and is the first large case series to be reported from an STD clinic in Africa.

\section{Patients and methods}

Patients with donovanosis attending the City Health STD Clinic situated at King Edward VIII Hospital, Durban, 1 January to 31 December 1988, were studied. Donovanosis was diagnosed by the detection of Donovan bodies on direct microscopy of tissue smears stained by the RapiDiff ${ }^{4}$ method and examined by trained medical and laboratory staff. Tissue smears were prepared from patients with GUD lesions of greater than $5 \mathrm{~mm}$ diameter that were suggestive of donovanosis, that is, beefy-red, well-demarcated non indurated ulcers without a rolled edge. Donovan bodies were detected by the characteristic appearances in mononuclear cells of multiple pink-purple bacillary bodies with an unstained capsule when stained by RapiDiff. The age, sex and recent place of residence of the patients and the duration, clinical appearances and site of lesions were recorded prospectively by medical staff. Lesions were classed as ulcero-granulomatous, hypertrophic, necrotic or sclerotic according to the clinical appearances described by Sehgal and Prasad. ${ }^{7}$ Two lesions were biopsied and histology sections were examined using the Giemsa stain.

Serological tests for syphilis (STS) were performed using the Treponema Pallidum
(GUD) that is found mainly in tropical areas amongst populations with poor socio-economic conditions and low standards of personal genital hygiene. Ulcers tend to have a characteristic beefy-red appearances without induration and bleed readily to the touch. In Africa dono- 
Table 1 Age and sex of patients with donovanosis

\begin{tabular}{|c|c|c|c|c|}
\hline \multirow[b]{2}{*}{ Age (years) } & \multicolumn{2}{|l|}{ Male } & \multicolumn{2}{|l|}{ Female } \\
\hline & $N=130$ & $\%$ & $N=41$ & $\%$ \\
\hline $16-19$ & 29 & $22 \cdot 3$ & 18 & 43.9 \\
\hline $20-29$ & 83 & 63.9 & 21 & $51 \cdot 2$ \\
\hline $30-39$ & 12 & $9 \cdot 2$ & 1 & $2 \cdot 4$ \\
\hline $40-49$ & 1 & 0.8 & 1 & $2 \cdot 4$ \\
\hline $50-59$ & 4 & $3 \cdot 1$ & - & - \\
\hline $60-69$ & 1 & 0.8 & - & - \\
\hline
\end{tabular}

Haemagglutination Assay (TPHA) and Rapid Plasma Reagin (RPR) methods. Following signed consent, 63 (48 men, 15 women) were tested for HIV antibody using a recombinant Diagnostics HIV-1 ELISA kit (Abbott Diagnostic) and positive sera confirmed by using the DuPont Western Blot (Biotech Research Laboratories). The study protocol for HIV testing was reviewed and approved by the Ethics Sub-Committee of the Faculty of Medicine, University of Natal.

The majority of patients were treated with co-trimoxazole, two tablets twice daily and were asked to return every week until complete re-epithelialisation of the ulcer-site was achieved. Minocycline $100 \mathrm{mg}$ twice daily was given in a few cases and erythromycin $500 \mathrm{mg}$ twice daily was prescribed during pregnancy.

\section{Results}

Donovan bodies were detected in tissue smears stained with RapiDiff from 169 (129 men, 40 women) and a histological diagnosis was made in two cases. The age and sex distribution of the 171 confirmed cases are shown in table 1 . The majority, $164(96 \%)$ were in the age range 1639. The male to female ratio was $3 \cdot 2: 1$. The duration of ulceration is shown in table 2 . An estimation of the incubation period was not possible. Many patients had either continued with sexual intercourse despite ulceration, denied recent sexual contact or had longstanding ulceration. Seventy two $(55.4 \%)$ of the men and $19(46.3 \%)$ of the women had ulcers for longer than 28 days prior to their attendance. Ninety five $(55.6 \%)$ patients came from rural areas. The majority of ulcers were of the ulcero-granulomatous variety (table 3 ). Hypertrophic ulcers were much less common. Six women were pregnant, three of whom had hypertrophic lesions. Only one man was circumcised.

The majority of ulcers were in the genital

Table 2 Duration of ulcers in patients with donovanosis

\begin{tabular}{|c|c|c|c|c|}
\hline \multirow[b]{2}{*}{ Duration (days) } & \multicolumn{2}{|l|}{ Male } & \multicolumn{2}{|l|}{ Female } \\
\hline & $N=130$ & $\%$ & $N=41$ & $\%$ \\
\hline $1-6$ & 1 & $0 \cdot 8$ & & \\
\hline $7-13$ & 13 & 1.0 & 9 & 21.9 \\
\hline $14-20$ & 20 & $15 \cdot 4$ & 11 & $26 \cdot 8$ \\
\hline $21-28$ & 24 & $18 \cdot 5$ & 2 & 4.9 \\
\hline $29-60$ & 31 & $31 \cdot 0$ & 5 & $12 \cdot 2$ \\
\hline $61-180$ & 26 & $20 \cdot 0$ & 6 & $14 \cdot 6$ \\
\hline $181-365$ & 10 & $7 \cdot 7$ & 6 & $14 \cdot 6$ \\
\hline $1-2$ years & 5 & $3 \cdot 8$ & 2 & 4.9 \\
\hline
\end{tabular}

area alone (table 4). Lesions in both genital and inguinal areas were more common in women than in men. One case of anal donovanosis was detected in a woman and none in men. Amongst males, most ulcers were subpreputial and situated either on the glans, shaft or coronal sulcus. Amongst women ulcers were situated at the fourchette in 20, cervix and vaginal vault in two and diffusely in the vulval area in the remainder. Pseudo-elephantiasis of the vulva was observed in three women.

Confirmation of the diagnosis was made by tissue smear examination in all except two patients with necrotic and hypertrophic ulcers from whom biopsies were obtained. Twenty one (15 women, six men) regular sexual contacts of patients with donovanosis were examined and Donovan bodies detected in only one couple, both with lesions in the inguinal region but without genital ulcers. None of these contacts had genital ulcers. Positive TPHA and RPR tests were detected in $40(23.4 \%)$, (29 men, 11 women) and positive TPHA and RPR $\geqslant 1: 8$ in $24(14 \%),(16$ men and eight women).

Forty one $(24 \%)$ were discharged as cured when reviewed at follow up, cure being defined as complete re-epithelialisation of ulcers. Almost all of the patients responded to cotrimoxazole. However, Donovan bodies were detected in five men after at least two weeks initial therapy. Donovan bodies were detected in one man seven weeks after a five week course of co-trimoxazole, and in a further four men at one, two, three and six months respectively after at least two weeks treatment with cotrimoxazole.

HIV-1 antibodies were detected in four of the men and none of the women who were tested for HIV-1. Three of the men returned for follow up. Complete cure was observed in all three after a two week course of cotrimoxazole.

\section{Discussion}

The majority of donovanosis lesions were ulcero-granulomatous. Hypertrophic ulcers were uncommon but were observed in three of six pregnant women. During pregnancy atypical lesions may progress rapidly ${ }^{8}$ and donovanosis should be suspected in women attending antenatal clinics with unusual genital ulcers. The sclerotic type of donovanosis was not observed and biopsy may be required for definitive diagnosis of this variant. Pseudoelephantiasis was more prevalent in women and may reflect the different lymphatic drainage between the sexes.

Careful preparation of tissue smears was considered imperative to maximise the yield of Donovan-body-positive smears on microscopy. When donovanosis was suspected clinically the ulcer was cleaned and a tissue smear prepared from the first swab applied to the ulcer. Subsequent swabs taken to detect other possible causes of GUD did not usually contain sufficient material for examination. Multiple application of swabs to ulcers may cause bleeding and interfere with microscopic assessment. The rapid stain used was simple 
Table 3 Clinical types of donovanosis

\begin{tabular}{|c|c|c|c|c|}
\hline \multirow[b]{2}{*}{ Clinical type } & \multicolumn{2}{|l|}{ Male } & \multicolumn{2}{|l|}{ Female } \\
\hline & $N=130$ & $\%$ & $N=41$ & $\%$ \\
\hline Ulcero-granulomatous & 125 & $96 \cdot 2$ & 37 & $90 \cdot 2$ \\
\hline Hypertrophic & 4 & $3 \cdot 1$ & 4 & $9 \cdot 8$ \\
\hline Necrotic & 1 & 0.8 & - & - \\
\hline
\end{tabular}

Table 4 Site of lesion in donovanosis

\begin{tabular}{llllllr}
\hline & \multicolumn{2}{l}{ Male } & & \multicolumn{2}{l}{ Female } \\
\cline { 2 - 3 } \cline { 5 - 6 } Site & $N=130$ & $\%$ & & & $N=41$ & $\%$ \\
\hline Genital & 125 & $96 \cdot 2$ & & 32 & $78 \cdot 0$ \\
Inguinal & 3 & $2 \cdot 3$ & & 1 & $2 \cdot 4$ \\
Anal & - & - & & 1 & $2 \cdot 4$ \\
Genital and inguinal & 2 & $1 \cdot 5$ & & 7 & $17 \cdot 1$ \\
\hline
\end{tabular}

and cheap and easily performed by staff with basic microscopy skills.

The male to female ratio of $3 \cdot 2: 1$ was similar to the majority of donovanosis series elsewhere and also to that for new attenders at this clinic in 1989. ${ }^{9}$ Elsewhere in Southern Africa studies with limited numbers of donovanosis in Zambia $^{10}$ and Eastern Transvaal, South Africa ${ }^{11}$ have diagnosed more cases in women than men but these reports included a preponderance of pregnant women who were diagnosed following biopsy.

Delay in the presentation of donovanosis was observed frequently. Longstanding donovanosis was common in the pre-antibiotic era and was also observed in significant numbers of patients in this study. Late presentation may reflect poor educational standards, ignorance of STD or the absence of suitable medical facilities. Many patients travelled from rural areas where there are no designated specialist clinics and STD cases are managed at the primary health care level. Donovanosis lesions may sometimes be extensive and in these rural settings patients may experience shame, embarrassment or ridicule from staff who are unsympathetic to those with STD.

Anal lesions were observed in only one woman in contrast to India where perianal lesions were observed in $7 \%$ in one study. ${ }^{12}$ Amongst Zulu men and women anal intercourse is an uncommon sexual behaviour ${ }^{13}$ and it is rare for patients at this clinic to complain of rectal symptoms secondary to STD. Inguinal lesions were uncommon in men and most ulcers were situated on the penis. This finding supports the use of "donovanosis" rather than "granuloma inguinale" as the definitive name for this condition. Confusion between donovanosis, granuloma inguinale, lymphogranuloma venereum, granuloma venereum and lymphogranuloma inguinale has undoubtedly led to misdiagnosis and there is a need for consistent terminology to be applied if such errors are to be avoided in the future.

Co-existent infection with donovanosis was detected in only one of 21 regular sexual partners examined. This low transmission rate is similar to the $1 \%$ in the USA ${ }^{14}$ and Papua New Guinea ${ }^{15}$ but much lower than the $50 \%,{ }^{12}{ }^{16}$ in India where those infected tended to be long term sexual partners. However, elsewhere in India where different social habits and customs may apply, low transmission rates have led to debate over the classification of donovanosis as an STD. ${ }^{17}$

Positive syphilis serology was detected in 40 $(23 \%)$ of our patients and may reflect both the high prevalence of syphilis in men and women locally ${ }^{1819}$ and the practice of sexual intercourse despite long-standing GUD in this community. ${ }^{13}$ Mixed infections with syphilis and other causes of GUD are common in Durban and often lead to atypical appearances that do not fit classical textbook descriptions.

Previous studies of donovanosis in India have reported a preponderance of cases amongst uncircumcised men. ${ }^{20}$ It is therefore noteworthy that only one man in this study was circumcised and that circumcision is also not practised routinely amongst black communities in Zambia ${ }^{10}$ and Zimbabwe ${ }^{21}$ where donovanosis is endemic. Most of the men in this study had poor standards of personal genital hygiene-retraction of the foreskin often revealed a moist environment with atrophy of the superficial mucosa and areas of deep pitting along the coronal sulcus following poor healing of previous episodes of GUD. Initiation of simple health education measures to prevent GUD by stressing the importance of personal hygiene together with advice on simple retraction of the foreskin and cleansing with soap, salt and water, could be an effective HIV prevention strategy that would require only a modest increase in resources.

Treatment with benzathine penicillin and another single dose antibiotic effective against chancroid are recommended for the management of GUD in HIV seronegative individuals in the tropics. However, both single dose ceftriaxone ${ }^{22}$ and spectinomycin ${ }^{23}$ are ineffective for donovanosis and prolonged antibiotic treatment may be necessary to effect complete cure. Most patients in this study were treated with co-trimoxazole for 14 days but in some cases treatment for up to 5 weeks was required. Donovan bodies were detected in five men who relapsed following initial improvement but it was uncertain whether this reflected antibiotic resistance or reinfection. Minocycline was given in a few cases but clinical improvement was slower than with co-trimoxazole. Complete healing of the ulcer site was observed in only $41(24 \%)$. Whether the remainder were cured or resumed sexual intercourse before healing is unknown. Ideally, follow up of patients with donovanosis should be undertaken so that re-epithelialisation of ulcers can be observed. At the same time, health education and counselling on the risks of HIV transmission could be given. Men with GUD and donovanosis in particular are a key core group at risk of both acquiring and transmitting HIV infection locally ${ }^{13}$ and need to be targeted specifically with health education information promoting safer sexual practices.

Further studies are required to determine whether HIV-1 sero-positive patients with donovanosis respond to treatment in the same way as those without HIV-1 infection. The 
three seropositive men with donovanosis who reattended were cured as expected but failure to respond to extended courses of antibiotics has been reported in two cases from South America. ${ }^{24}$ All three of the men from Durban had no HIV-related symptoms and probably contracted HIV infection relatively recently given that HIV-1 infection was only identified amongst attenders at this clinic a few months before this study commenced. ${ }^{25}$

Previous studies have shown that the clinical diagnosis of GUD is often inaccurate ${ }^{2627}$ even when the possible causes are limited. In Durban all of the STD causes of GUD including donovanosis are prevalent and difficult clinical diagnostic problems are often encountered. However, knowledge of both the aetiology and epidemiological trends of GUD locally may improve clinical acumen. Although donovanosis was not diagnosed in a previous study of GUD in Durban in $1985^{3}$ the clinical diagnostic accuracy of donovanosis is high compared to other causes of GUD (unpublished data) and may reflect a recent increase in the number of cases identified. ${ }^{28}$

Early recognition and treatment of donovanosis should now be included in strategies to limit the spread of HIV-1 in Southern Africa. Both the rapid increase in, and burden of HIV 1 infection, not only in urban but also in rural areas of Natal and Kwazulu ${ }^{2930}$ where high prevalences of STDs prevail, ${ }^{31}$ justify urgent initiatives directed towards the management of GUD and donovanosis. Increased resources to improve STD service delivery at the primary health care level in all settings should be a priority and could lead to the eradication of donovanosis in this community.

The author thanks Mr K Coetzee, Department of Microbiology, University of Natal Medical School, Mr B Zulu, Durban City Health Department for technical assistance and all doctors, nursing sisters and health assistants for their co-operation in the study.

1 McElligot GLM. Venereal disease in the tropics. $\mathrm{Br} J$ Venereal Dis 1951;27:122-6.

2 Osoba AO. Sexually transmitted diseases in tropical Africa. Br J Venereal Dis 1981;57:89-94.

3 Coovadia YM, Kharsany A, Hoosen AA. The microbial aetiology of genital ulcers in black men in Durban, South Africa. Genitourin Med 1985;61:266-9.

4 O'Farrell N, Hoosen AA, Coetzee K, van den Ende J. A rapid stain for the diagnosis of granuloma inguinale. Genitourin Med 1990;66:200-1.

5 WHO. Prevention of sexual transmission of human immunodeficiency virus. WHO AIDS: Series 6. 1990.
6 O'Farrell N, Windsor I, Becker P. HIV-1 infection among heterosexual attenders at a sexually transmitted diseases clinic in Durban. S Afr Med J 1991;80:17-20.

7 Sehgal VN, Prasad AL. Donovanosis-current concepts. Int J Derm 1986;25:8-16.

8 Wilson LA. Pregnancy and labour complicated by granuloma inguinale. JAM $A$ 1930;95:1093-5.

9 Durban City Health Department. Annual Report of the Medical Officer of Health for Durban 1989.

10 Bhagwandeen BS, Naik KG. Granuloma venereum (granuloma inguinale) in Zambia. E Afr Med J 1977;54:637-42.

11 Freinkel AL. Granuloma inguinale (donovanosis). Southern African Journal of Sexually Transmitted Diseases 1984 4:43-7.

12 Lal S, Nicholas C. Epidemiological and clinical features in 165 cases of granuloma inguinale. Br J Venereal Dis 1970 ; 46:461-3.

13 O'Farrell N, Hoosen AA, Coetzee K, van den Ende J. Sexual behaviour in Zulu men and women with genital ulcer disease. Genitourin Med 1992;68:245-8.

14 Packer H, Goldberg J. Studies of the antigenic relationship of D. granulomatis in members of the tribe Escherichiae. American Journal of Syphilis 1950;34:342-50.

15 Maddocks I, Anders EM, Dennis E. Donovanosis in Papua New Guinea. Br J Venereal Dis 1976;52:190-6.

16 Bedi BM, Garg BR, Lal S, Nicholas C. Clinicoepidemiological studies on 189 cases of donovanosis. Indian Journal of Dermatology $\mathcal{E}$ Venereology 1975;41 1-3.

17 Nair VG, Pandalai NG. Granuloma genitoinguinale. Indian Medical Gazette 1934;69:361-75.

18 O'Farrell N, Hoosen AA, Coetzee K, van den Ende J. Genital ulcer disease in men in Durban, South Africa. Genitourin Med 1991;67:327-30.

19 O'Farrell N, Hoosen AA, Coetzee K, van den Ende J. Genital ulcer disease in women in Durban, South Africa. Genitourin Med 1991;67:322-6.

20 Rajam RV, Rangiah PN. Donovanosis (Granuloma inguinale, granuloma venereum). Geneva: World Health Organisagranuloma venereum). Geneva: World Health Orga
tion. WHO Monograph Series No. 24, 1954:1-72.

21 Latif AS, Mason PR, Paraiwa A. The treatment of donovanosis (granuloma inguinale). Sex Transm Dis 1988;15:27-9.

22 O'Farrell N. Failure of single dose ceftriaxone in donovanosis. Genitourin Med 1991;67:269-70.

23 O'Farrell N. Failure of single dose spectinomycin in donovanosis. Trans R Soc Trop Med Hyg 1990;84:862.

24 Jardim ML, Barros ER, Silveira M. Donovanose em pacientes portadores de AIDS. Relato de dois casos. Anais Brasileiros de Dermatologia e Sifolographia 1990;65:175-7.

25 O'Farrell N, Windsor I. Prevalence of HIV antibody in recurrent attenders at a sexually transmitted diseases clinic. $S$ Afr Med J 1988;74:104-5.

26 Chapel TA, Brown WJ, Jeffries C, Stewart JA. How reliable is the morphological diagnosis of penile ulcerations? Sex Transm Dis 1977;4:150-2.

27 Fast MW, D'Costa LJ, Nsanze H, et al. The clinical diagnosis of genital ulcer disease in the tropics. Sex Transm Dis 1984;11:72-6.

28 O'Farrell N. Trends in reported cases of donovanosis in Durban, South Africa. Genitourin Med (in press).

29 Department of National Health and Population Development. Second National HIV survey of women attending antenatal clinics, South Africa, October/November 1991. Epidemiological Comments 1992;19:80-92.

30 Kemp TN, McAnyana P. The clinical experience of the HIV epidemic in a regional Kwazulu hospital. Joint Congress of the Infectious Diseases Society of South Africa and the Sexually Transmitted Diseases Society of Southern Africa. Capetown, 4-6 September 1991.

31 O'Farrell N, Hoosen AA, Kharsany ABM, van den Ende J. Sexually transmitted pathogens in pregnant women in a rural South African community. Genitourin Med 1989;65: 276-80. 